\title{
Chikungunya fever in Canada: fever and polyarthritis in a returned traveller
}

\author{
Kevin L. Schwartz MD, Aliyah Giga DC, Andrea K. Boggild MD
}

See also practice article on page 775 and at www.cmaj.ca/lookup/doi/10.1503/cmaj.140031.

Competing interests: Andrea Boggild has received lecture fees from the American Society for Microbiology. No other competing interests were declared.

This article has been peer reviewed.

Correspondence to: Andrea Boggild, andrea.boggild@utoronto.ca

CMAJ 2014. DOI:10.1503 /cmaj.130680
A previously healthy 28 -year-old woman from Canada experienced extensive mosquito bites while visiting Mumbai, India, in September 2010. Twelve days into her trip, an acute onset of fever, chills and severe joint pain developed, primarily affecting her wrists, neck and ankles. While in India, she received treatment for presumptive malaria and was given parenteral analgesia. After three days, her fever resolved. In addition to fever and joint pain, she reported skin hyperpigmentation on the bridge of the nose. During her convalescence, there was no recurrence of fever, but she remained unable to extend and rotate her wrists, dorsiflex, plantar flex, or internally or externally rotate her ankles without substantial pain.

Two and a half months after her initial symptoms, our patient was referred to a tropical disease restricted range of motion in the wrists, ankles and neck with minimal relief from the nonsteroidal anti-inflammatory drug celecoxib. On physical examination, she had normal vital signs and there was no evidence of lymphadenopathy, hepatosplenomegaly or joint effusions. A complete blood count showed a hemoglobin level of 145 (normal $120-160$ ) g/L, a platelet count of 292 (normal $150-400) \times 10^{\circ} / \mathrm{L}$ and a leukocyte count of 7.3 (normal 3.5-12) $\times 10^{9} / \mathrm{L}$ with a total eosinophil count of 0.61 (normal $0.05-0.4$ ) $\times 10^{9} / \mathrm{L}$. At the top unit. She reported persistent joint pain with

of our differential diagnosis were chikungunya fever, dengue fever and rickettsial infection. Box 1 summarizes key clinical features of chikungunya and dengue infections. ${ }^{1}$ Serologic investigations showed an elevated titre to chikungunya immunoglobulin $\mathrm{G}(\mathrm{IgG})$ antibodies at 1:160 (positive $>1: 10$ by hemagglutination inhibition assay). Dengue IgG antibodies were reactive, but immunoglobulin $\mathrm{M}(\mathrm{IgM})$ was nonreactive; test results for rickettsia were nonreactive. Based on these results, rickettsial disease was excluded. The persistent arthralgia combined with a negative dengue IgM suggested false-positive (cross-reactive) dengue $\mathrm{IgG}$, which can be seen after infections with, or vaccinations against, other flaviviruses, such as yellow fever, Japanese encephalitis and West Nile virus. The elevated antibody titres to chikungunya virus and the clinical course were diagnostic of chikungunya fever. Ibuprofen and physical therapy were recommended as treatment. Our patient had function-limiting arthralgia and reduced range of motion at the wrists, which slowly improved over an 18-month period. Restoration of baseline status had not been achieved by two years after the infection.

\section{Discussion}

Chikungunya is an emerging arboviral infection among travellers and one that Canadian physicians are increasingly likely to encounter. ${ }^{2}$ Chikungunya fever is caused by the chikungunya virus, which is spread by the Aedes aegypti mosquito and less commonly by A. albopictus. ${ }^{1}$ Chikungunya, a word from the Makonde language, means "that which bends up," referring to the stooped posture that results from arthritic symptoms.

Other viruses to consider as a cause of fever and arthritis include parvovirus B19 as well as other alphaviruses, most of which can be differentiated based on geographic location. Ross River virus and Barmah Forest virus are indigenous to Australia. O'nyong-nyong and Semliki Forest 
viruses are found in Africa, whereas Sindbis virus is distributed in Africa, Europe, Asia and Australia. Mayaro virus is restricted to Latin America, though cases were first described in the Caribbean.

\section{Epidemiology}

Chikungunya virus was first isolated in 1953 in Tanzania during an epidemic outbreak in East Africa. ${ }^{3}$ An outbreak of febrile illness in 2004 on Lamu Island, Kenya, was originally presumed to be malaria. Local clinicians identified the unusual predominance of joint pain with negative results on malaria smear tests. A cross-sectional seroprevalence study revealed that $75 \%$ of the island's population had been infected. ${ }^{4}$ Over the subsequent 18 months, there were several large outbreaks of chikungunya virus in the area, including on the Comoros and Réunion islands, resulting in roughly half a million cases. ${ }^{5}$ Chikungunya was imported to France from Réunion, with 47 travellers having confirmed chikungunya virus in 2006, prompting the need for global awareness in nonendemic countries. ${ }^{5}$ In 2006, chikungunya virus entered India, which led to more than 1 million cases. There have also been confirmed reports of Chikungunya fever in travellers returning to Canada, ${ }^{6}$ the United States ${ }^{2}$ and Europe. ${ }^{7}$

In geographic locations with favourable environmental conditions and competent vectors, chikungunya virus can spread locally. Increasing temperatures and rainfall in parts of North America are expected to favour the propagation of a number of vector-borne diseases, including chikungunya virus. ${ }^{8}$ There has been a recently described outbreak of hundreds of cases in Italy initiated by a traveller returning from India. ${ }^{7}$ There is ongoing disease activity in Indonesia, Papua New Guinea, the Philippines and India; more than 100 cases, most believed to have originated in Indonesia, have been reported in Australia. As of December 2013, autochthonous chikungunya virus has emerged in the western hemisphere, with a large ongoing outbreak in the Caribbean. Probable or confirmed cases numbering in the hundreds have occurred in St. Martin and Martinique, with locally transmitted cases also occurring in Saint Barthélemy, Guadeloupe, Sint Maarten and the British Virgin Islands as of the time of writing. (Frequent updates on outbreaks of chikungunya virus can be found on ProMED [Program for Monitoring Emerging Diseases]; Box 2).

\section{Clinical presentation}

Chikungunya fever has two stages of illness: acute and chronic. The acute phase presents similarly to dengue fever, with fever, asthenia, headache, myalgia, arthralgia and rash. The chronic phase is characterized by disabling poly- arthritis of variable duration and affects most, but not all, patients. ${ }^{1}$ An important feature of chikungunya is the severity and chronicity of joint symptoms, including arthritis and arthralgia. The classic retro-orbital pain and hemorrhagic findings typical of dengue fever and dengue hemorrhagic fever, respectively, are rare with chikungunya infection. ${ }^{1}$ In $90 \%$ of cases, the illness begins suddenly with fever and joint pain after an incubation period of 2 to 10 days. The median duration of fever is four (range two to seven) days. Joint pain is commonly distal and symmetric, involving wrists, ankles, phalanges, knees, elbows and shoulders. ${ }^{5}$ A maculopapular rash may appear concurrently but is more common several days into the illness. ${ }^{5}$ Fatalities are rare. ${ }^{5}$ Vertical transmission from viremic mothers to neonates has been reported, with some cases progressing to fatal encephalitis. ${ }^{1}$

The duration of joint pain is variable across reports but ranges anywhere from weeks to years and from mild discomfort to severe disability.

\section{Diagnosis}

The diagnosis of chikungunya fever starts with clinical suspicion, but many of the symptoms are nonspecific and are also observed in dengue fever, which shares endemicity with chikungunya fever. Polymerase chain reaction (PCR)

\begin{tabular}{|lll|}
\hline Box 1: Clinical features of chikungunya and dengue viral infections \\
\hline Clinical feature & \multicolumn{1}{c|}{ Chikungunya } & \multicolumn{1}{c|}{ Dengue } \\
\hline Fever & Common & Common \\
\hline Myalgia & Possible & Common \\
\hline Polyarthritis & Common & Unlikely \\
\hline Retro-orbital pain & Unlikely & Common \\
\hline Rash & Possible & Common \\
\hline $\begin{array}{l}\text { Leukopenia or } \\
\text { thrombocytopenia }\end{array}$ & Possible & Common \\
\hline Bleeding & Unlikely & Possible \\
\hline Chronic symptoms & $\begin{array}{l}\text { Polyarthritis for } \\
\text { months to years is } \\
\text { common }\end{array}$ & $\begin{array}{l}\text { Fatigue for many } \\
\text { months is common }\end{array}$ \\
\hline Modified from Thiboutot et al. ${ }^{1}$ & & \\
\hline
\end{tabular}

\section{Box 2: Resources for clinicians}

- Public Health Agency of Canada; www.phac-aspc.gc.ca/tmp-pmv/info /chikungunya-eng.php

- Chikungunya outbreak in the Caribbean, 2013-2014. Public Health Agency of Canada. www.phac-aspc.gc.ca/publicat/ccdr-rmtc/14vol40 /dr-rm40-02/dr-rm40-02-chik-eng.php

- Centers for Disease Control and Prevention; www.cdc.gov/chikungunya

- ProMED (Program for Monitoring Emerging Diseases); www.promedmail.org 
testing or virus isolation are possible within the first week of illness, with PCR having the greatest sensitivity. ${ }^{9}$ Polymerase chain reaction testing is available on an investigational basis through reference laboratories such as the National Microbiology Laboratory in Winnipeg, Manitoba. The most common method of diagnosis, as recommended by the US Centers for Disease Control and Prevention, is serologic detection of immunoglobulin M (IgM) or immunoglobulin $\mathrm{G}$ (IgG) antibodies, which may be falsely negative during the first week of symptoms. ${ }^{1}$ In patients with a high index of suspicion, convalescent serology can be performed four to six weeks later to improve sensitivity. Commercial and inhouse serologic assays, such as the hemagglutination inhibition assay (offered by the National Microbiology Laboratory), enzyme immunoassays or immunofluorescence assays, which detect circulating IgG antibodies to chikungunya virus and are reported to have varying sensitivities and specificities. ${ }^{9}$ Generally, assays detecting IgG antibodies have superior performance to those detecting IgM. ${ }^{9}$ Immunoglobulin $\mathrm{M}$ antibodies become detectable within two to six days of symptom onset and persist for weeks to months, whereas IgG antibodies first appear during convalescence and can persist for years. ${ }^{9}$

\section{Treatment}

There are no specific antiviral treatments for chikungunya fever in the acute stage; mainstays of therapy are supportive and include rest, antipyretics and analgesics. For chronic arthritis and arthralgia, there have been few controlled trials evaluating specific therapies. One trial involving 70 adults with confirmed infection with chikungunya virus and chronic arthralgia randomly assigned patients to receive $250 \mathrm{mg}$ of chloroquine sulfate or $7.5 \mathrm{mg}$ of meloxicam for 24 weeks. There was no significant difference observed in symptom resolution. ${ }^{10}$ Observational data on disease-modifying antirheumatic drugs, such as sulfasalazine and methotrexate, have shown some clinical benefit. ${ }^{11}$ Future studies are focusing on antirheumatic drugs for chronic symptoms.

\section{Prognosis}

A longitudinal study from Réunion found that $60 \%$ of patients had arthralgia 36 months after their acute illness. ${ }^{12}$ The arthralgia typically affected multiple joints and substantially affected activities of daily living and vocational and social functioning. ${ }^{12}$ Of patients with arthralgia for longer than three years, $70 \%$ have four or more joints involved and $20 \%$ will experience a relapse after resolution of symptoms. ${ }^{12}$ About half with persistent arthralgia have difficulties with activi- ties of daily living, and a quarter experience an impact on their working life. ${ }^{12}$ Pre-existing diabetes and age greater than 35 years were found to be predictive of chronic arthralgia; however, sex and viral load at the time of diagnosis were not. ${ }^{12}$

In addition, concurrent myalgia, cutaneous lesions and depression were common. Biological markers (e.g., C-reactive protein, antinuclear and anti-DNA antibodies) commonly seen in autoimmune and rheumatoid conditions were absent in patients with arthralgia, which suggests inflammation was more local than systemic. ${ }^{12}$

\section{Prevention}

At present, there is no vaccine available for chikungunya virus. Pretravel assessment and counselling regarding protective measures against mosquito bites, including diethyltoluamide-based insect repellents and clothing, is currently the most effective preventative measure.

\section{References}

1. Thiboutot MM, Kannan S, Kawalekar OU, et al. Chikungunya: A potentially emerging epidemic? PLoS Negl Trop Dis 2010;4: e623.

2. Gibney KB, Fischer M, Prince HE, et al. Chikungunya fever in the United States: a fifteen year review of cases. Clin Infect Dis 2011;52:e121-6.

3. Lumsden WHR. An epidemic of virus disease in Southern Province, Tanganyika territory, in 1952-53. II. General description and epidemiology. Trans R Soc Trop Med Hyg 1955;49:33-57.

4. Sergon K, Njuguna C, Kalani R, et al. Seroprevalence of chikungunya virus (CHIKV) infection on Lamu Island, Kenya, October 2004. Am J Trop Med Hyg 2008;78:333-7.

5. Simon F, Parola P, Grandadam M, et al. Chikungunya infection: an emerging rheumatism among travelers returned from Indian Ocean islands. Report of 47 cases. Medicine 2007;86:123-37.

6. Boggild AK, Geduld J, Libman M, et al. Travel acquired infections and illnesses in Canadians: surveillance report from CanTravNet surveillance data, 2009-2011. Open Med 2014;7:e20-e32.

7. Poletti P, Messeri G, Ajelli M, et al. Transmission potential of chikungunya virus and control measures: the case of Italy. PLoS ONE 2011;6:e18860.

8. Greer A, Ng V, Fisman D. Climate change and infectious diseases in North America: the road ahead. CMAJ 2008;178:715-722.

9. Niedrig M, Zeller H, Schuffenecker I, et al. International diagnostic accuracy study for the serological detection of chikungunya virus infection. Clin Microbiol Infect 2009;15:880-4.

10. Chopra A, Saluja M, Venugopalan A. Chloroquine effectiveness and inflammatory cytokine response in early persistent post chikungunya musculoskeletal pain and arthritis. Arthritis Rheum 2013;66:319-26.

11. Ganu MA, Ganu AS. Post-chikungunya chronic arthritis - our experience with DMARDs over two year follow up. $J$ Assoc Physicians India 2011;59:83-6.

12. Schilte C, Staikowsky F, Couderc T, et al. Chikungunya virusassociated long-term arthralgia: a 36-month prospective longitudinal study. [published in erratum in PLoS Negl Trop Dis 2013; 7: doi:10.1371] PLoS Negl Trop Dis 2013;7:e2137.

Affiliations: Department of Paediatrics (Schwartz), University of Toronto, Toronto, Ont.; Division of Infectious Diseases (Schwartz), The Hospital for Sick Children, Toronto, Ont.; Workplace Safety and Insurance Board of Ontario (Giga), Toronto, Ont.; Tropical Disease Unit, Division of Infectious Diseases (Boggild), Department of Medicine, University Health Network and University of Toronto, Toronto, Ont.; Laboratory Services (Boggild), Public Health Ontario, Toronto, Ont.

Contributors: All of the authors contributed to the literature review, and to writing and revising the article. All of the authors approved the version submitted for publication. 